\title{
OUTCOME IN NEWBORNS FROM PREGNANCIES AFTER IN VITRO FERTILIZATION
}

\author{
M.P. Senohradski, S. Vukovic-Zakic, T. Petrovic, M. Vasiljevic, S. Stanisic \\ Neonatology, Clinic of Gynecology and Obstetrics 'The National Front', Belgrade, Serbia
}

Background: Artificial reproductive technique - in vitro fertilization (IVF) has taken an important place in medicine as a routine and efficient method for the treatment of fertility.

Aim: To examine outcome in newborns from pregnancies after IVF.

Methods: A retrospective study included 260 newborns from pregnancies after IVF, which were divided into two groups. The first group consisted of 136 neonates from monofoetal IVF pregnancies and the second group consisted of 124 neonates from multifoetal IVF pregnancies. In newborns were analyzed: gender, gestation, anthropometric measures, Apgar score, morbidity and outcome.

Results: The study found no difference in sex distribution between both groups of newborns from IVF pregnancies $(\mathrm{p}>0.05)$. Analysis found a significantly higher gestational age (37.6gw vs. $35.0 \mathrm{gw}, \mathrm{p}<0.01)$, lower rate of prematurity $(20.5 \%$ vs. $64.5 \%, \mathrm{p}<0.01)$, greater birth body weight $(3098.5 \mathrm{~g}$ vs. $2238.7 \mathrm{~g}, \mathrm{p}<$ $0.01)$ and body length $(49.9 \mathrm{~cm}$ vs. $45.5 \mathrm{~cm}, \mathrm{p}<0.01)$ in neonates from monofoetal IVF pregnancies. Analysis found significantly higher values of Apgar score at the first $(8.5 \mathrm{vs.} 7.0, \mathrm{p}<0.01)$ and at the fifth minute $(9.3$ vs. 7.8, $\mathrm{p}<0.01)$ of birth in newborns from monofoetal IVF pregnancies. Testing has found a significantly lower morbidity in the first group of neonates $(40.4 \%$ vs. $71.8 \%, \mathrm{p}<0.01)$, respectively, higher number of newborns from monofoetal IVF pregnancies had a favorable outcome $(89.7 \%$ vs. $59.6 \%, \mathrm{p}<0.01)$.

Conclusion: Newborns from monofoetal IVF pregnancies have a lower potential risk of perinatal complications with lower morbidity and better outcome, unlike newborns from multifoetal IVF pregnancies. 